\title{
Mieloma Múltiplo: 50 casos diagnosticados por citometria de fluxo
}

\author{
Multiple Myeloma: 50 cases diagnosed by flow cytometry
}

\author{
Mariana F. A. Funari ${ }^{1}$ \\ João C. C. Guerral \\ Euripides Ferreira ${ }^{l}$ \\ Jacyr Pasternak ${ }^{l}$ \\ Cleide L. Borovik ${ }^{1}$ \\ Ruth H. Kanayama ${ }^{1}$ \\ Sônia T. Nozawa \\ Cláudio E. A. Mendes ${ }^{l}$ \\ Ana C. M. Brito \\ Marcelo H. W. Faulhaber \\ Nydia S. Bacal
}

\begin{abstract}
O Mieloma Mútiplo é uma doença de evolução heterogênea, na qual a maioria dos pacientes recai muito precocemente após o tratamento. Nesse contexto, o objetivo principal deste trabalho é relatar diferentes estratégias de análise do mieloma por citometria de fluxo e sua importância na associação com citogenética no diagnóstico de doença residual. Entre 2.450 casos de doenças onco-hematológicas estudados, de setembro de 1993 a agosto de 2004, foram diagnosticados 50 (2,0\%) Mieloma Múltiplo. Foram feitas análises morfológicas e, até o ano de 2000, as imunofenotipagens foram realizadas no citômetro de fluxo XL-MCL (Coulter) pela estratégia tamanho/ complexidade, utilizando os anticorpos monoclonais CD19, CD20, CD38, CD45, CD56, HLA-DR, kappa e lambda de superficie e intracitoplasmáticas. A partir de 2001 passaram-se a utilizar painéis seqüenciais através do histograma CD138/ Complexidade e anticorpos monoclonais CD19, CD38, CD56, CD117, kappa e lambda intracitoplasmáticas. Mais recentemente foram incluidos no painel os anticorpos CD45, HLA-DR e CD33. A análise do DNA foi realizada por citometria com auxílio do programa Multicycle em nove amostras, sendo que sete apresentaram população aneuplóide. O cariótipo com banda $G$ foi realizado em 25 casos, e a pesquisa de deleção do 13q por FISH em 15. Alterações cromossômicas foram encontradas em 4 casos, sendo duas deleções de $13 q$ confirmadas por FISH. A mudança na estratégia de gates associada à citogenética e ao estudo da cinética do ciclo do DNA permitem melhor identificação de células plasmáticas anômalas, avaliação do prognóstico e deteç̧ão de doença residual. Rev. bras. hematol. hemoter. 2005;27(1):31-36.
\end{abstract}

Palavras-chave: Mieloma Múltiplo; citometria de fluxo; citogenética; doença residual.

\section{Introdução}

O Mieloma Múltiplo (MM) é a segunda doença oncohematológica mais comum no mundo, perdendo apenas para os linfomas e chegando a representar $10 \%$ dos casos. ${ }^{1}$ É uma doença caracterizada pela proliferação descontrolada de células plasmáticas na medula óssea com freqüente produção de imunoglobulinas anômalas monoclonais (proteína $\mathrm{M}$ ). Sua prevalência é maior a partir da quinta década de vida. ${ }^{2}$

Trata-se de uma doença com evolução heterogênea cuja sobrevida dos pacientes pode variar de alguns meses até mais de uma década. ${ }^{3}$ Os critérios para o diagnóstico estão bem estabelecidos ${ }^{4}$ (Tabela1). A maioria dos casos evolui com anemia grave, lesões ósseas, insuficiência renal e infecções recorrentes. Esse quadro é resultado de uma infiltração maciça da medula óssea, reabsorção óssea estimulada por citocinas produzidas pelas células tumorais, depósito de cadeias leves monoclonais nos túbulos renais e imunoglobulina monoclonal ineficiente. ${ }^{5}$

O mau prognóstico dos pacientes com MM tem levado a busca de novas opções terapêuticas, incluindo o transplante com células progenitoras. Apesar disso, os pacientes recaem precocemente devido à persistência de células tumorais não visíveis na análise morfológica. Os plasmócitos

${ }^{I}$ Departamento de Patologia Clinica do Hospital Albert Einstein - São Paulo-SP - Brasil.

Correspondência para: Nydia Strachman Bacal

Av. Albert Einstein, $6274^{\circ}$ andar - Morumbi

05651-901 - São Paulo-SP

Tel.: (11) 3747-2430 / Fax: (11) 3747-2122.

Email:nsbacal@einstein.br 
Tabela 1

Critérios de diagnóstico em Mieloma Múltiplo

\begin{tabular}{|c|c|}
\hline \multicolumn{2}{|c|}{ Critérios maiores } \\
\hline 1. & Plasmocitoma em biópsia de tecido \\
\hline 2. & Plasmocitose na medula óssea maior que $30 \%$ \\
\hline 3. & $\begin{array}{l}\text { Pico monoclonal de imunoglobulina na eletroforese de } \\
\text { proteínas séricas com lgG maior que } 3,5 \mathrm{~g} / \mathrm{dL} \text { ou } \mathrm{lgA} \\
\text { maior que } 2,0 \mathrm{~g} / \mathrm{dL} \text {; excreção de cadeia leve kappa ou } \\
\text { lambda maior que } 1,0 \mathrm{~g} / \mathrm{dL} \text { em urina de } 24 \text { horas }\end{array}$ \\
\hline \multicolumn{2}{|r|}{ Critérios menores } \\
\hline a. & Plasmocitose na medula óssea entre $10 \%$ e $30 \%$ \\
\hline b. & $\begin{array}{l}\text { Pico monoclonal de imunoglobulina em níveis inferiores } \\
\text { aos citados }\end{array}$ \\
\hline c. & Lesões osteolíticas \\
\hline & $\begin{array}{l}\text { Diminuição dos níveis das imunoglobulinas não envolvidas } \\
\text { (lgM menor que } 50 \mathrm{mg} / \mathrm{dL} \text {, } \operatorname{lgA} \text { menor que } 100 \mathrm{mg} / \mathrm{dL} \text {,ou } \\
\operatorname{lgG} \text { menor que } 600 \mathrm{mg} / \mathrm{dL} \text { ) }\end{array}$ \\
\hline \multicolumn{2}{|r|}{ Qualquer uma das associações abaixo confirma o diagnóstico: } \\
\hline \multicolumn{2}{|r|}{ Dois critérios maiores } \\
\hline \multicolumn{2}{|r|}{ Critério maior 1 associado a um critério menor b, c, ou d } \\
\hline \multicolumn{2}{|r|}{ Critério maior 3 associado a um critério menor a ou c } \\
\hline & Três critérios menores ( $a, b$ e c, ou a, b e d) \\
\hline
\end{tabular}

Adaptado de Durie BMG. Staging and kinetics of multiple myeloma. Semin Oncol 1986;13:300-309.

malignos expressam em sua superfície marcadores que normalmente não estão presentes nos plasmócitos normais. ${ }^{6}$ Dessa forma, a imunofenotipagem auxilia de maneira significativa na identificação de populações de células plasmocitárias anômalas. Nesse contexto, o objetivo principal desse trabalho é relatar diferentes estratégias de análise do MM por citometria de fluxo e sua importância, em associação com o estudo citogenético, na detecção de doença residual.

\section{Casuística e Métodos}

No Laboratório Clínico do Departamento de Patologia Clínica do Hospital Albert Einstein, de setembro de 1993 a agosto de 2004, foram analisados por citometria de fluxo 3.583 painéis proliferativos, sendo $2.450(68,4 \%)$ de doenças oncohematológicas.

Entre os casos de doenças onco-hematológicas foram diagnosticados 50 (2\%) novos casos de MM em 49 (98\%) amostras de aspirado de medula óssea e uma (2\%) de sangue periférico. A idade média ao diagnóstico foi 61,3 anos e a relação masculino/feminino de 2,1:1.

As análises morfológicas foram realizadas em lâminas coradas pelo método pancromático de May-GrünwaldGiemsa. Foram observadas células plasmáticas características de tamanho moderado, núcleo redondo e excêntrico, algumas com nucléolos, cromatina regular e citoplasma basofílico com halo perinuclear (Figura 1). Agrupamentos de plasmócitos displásicos e plasmoblatos também foram visualizados em alguns casos.

Para a imunofenotipagem, no início, as amostras eram preparadas através de separação das células em FicollHypaque. Posteriormente, por métodos de preparação em QPREP (Coulter) ou com tampão hemolítico. As análises imunofenotípicas foram realizadas no citômetro de fluxo XLMCL (Coulter). No período de 1993 a 2000 foram utilizados os anticorpos monoclonais CD19, CD20, CD45, CD38, CD56, kappa e lambda de superfície e intracitoplasmáticas, numa estratégia de tamanho/complexidade (Figura 2).

A partir de 2001, o painel foi modificado e passou-se a utilizar painéis seqüenciais através do histograma CD138/ complexidade e anticorpos monoclonais CD19, CD38, CD56,

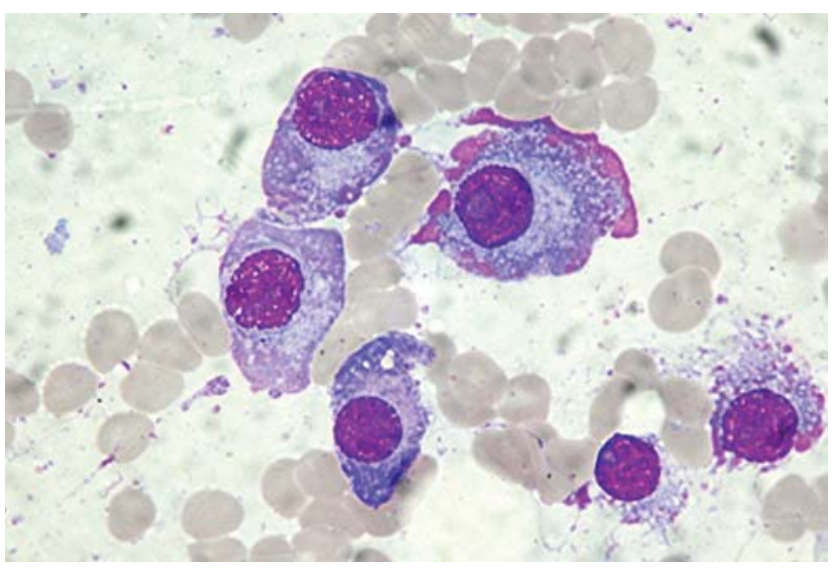

Figura 1. Células do mieloma na medula óssea

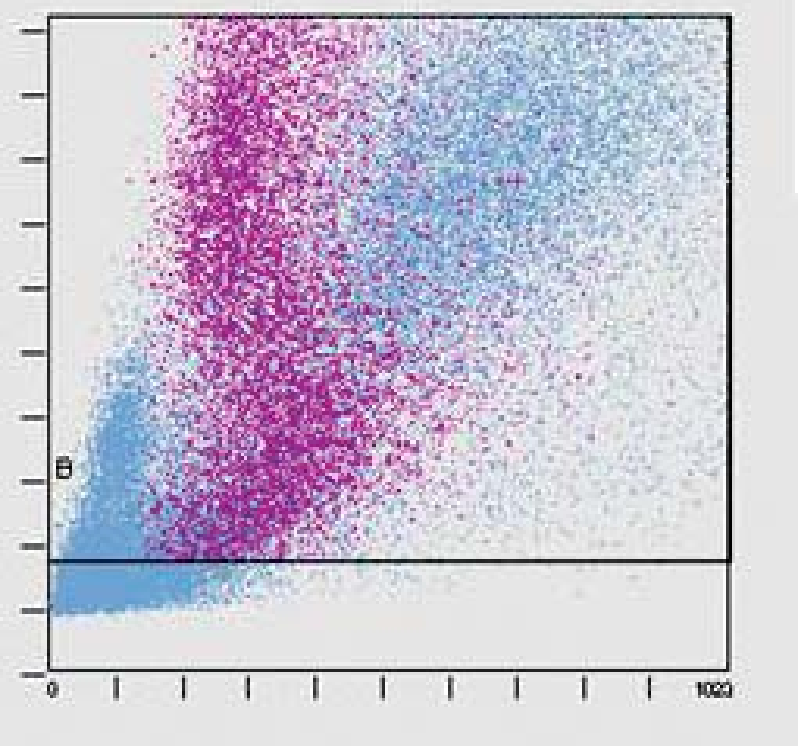

Figura 2. Histograma Tamanho x Complexidade 
CD117 (Figuras 3, 4 e 5). As marcações das imunoglobulinas intracitoplasmáticas de cadeia leve foram atreladas à população CD38(+). Nos casos mais recentes foram avaliados também o CD45, o HLA-DR e o CD33 (Figuras 6 e7). A densidade antigênica foi avaliada através do canal médio de expressão em escala logarítmica obtida nos histogramas.

A análise do conteúdo de DNA foi realizada em nove (18\%) amostras que foram marcadas com iodeto de

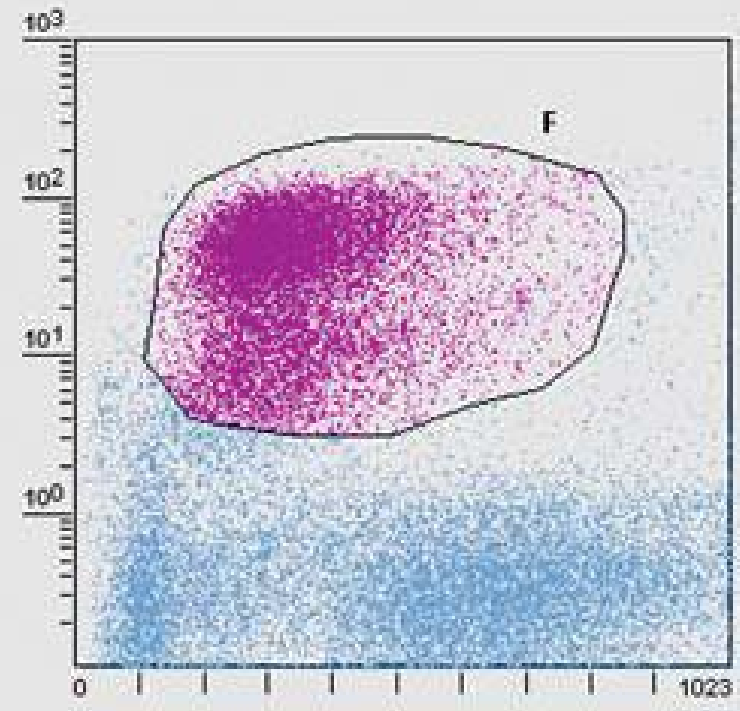

Figura 3. Histograma CD138 x Complexidade

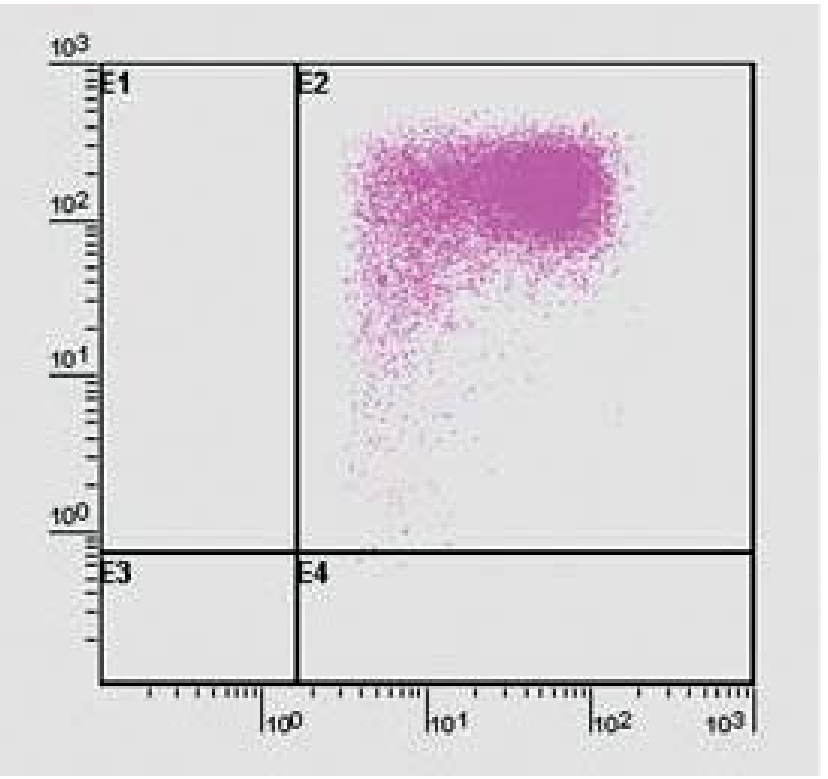

Figura 4. Histograma CD138 x CD38 propidium no DNA-PREP (Coulter). A cinética do ciclo do DNA foi analisada no citômetro de fluxo equipado com o programa Multicycle.

O estudo citogenético foi realizado a partir de culturas de 24-48 horas e/ou 72-96 horas com adição de Phorbol (Sigma) como estimulante. O cariótipo com banda $\mathrm{G}$ foi realizado em 25 (50\%) casos e a pesquisa de deleção do 13q por FISH com a sonda LSI D13S319 (Vysis, Inc.) em 15 (30\%) casos.

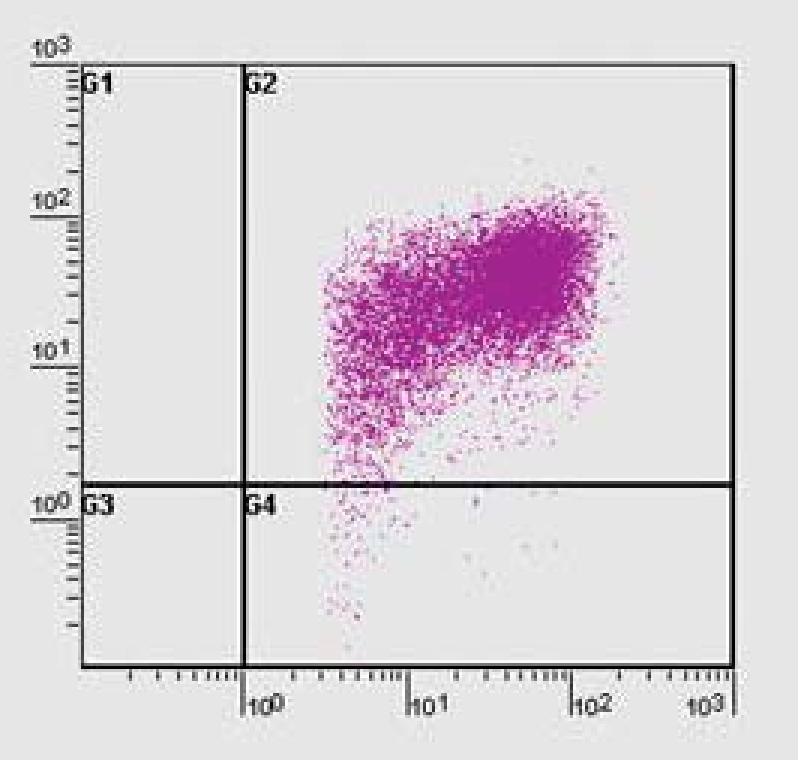

Figura 5. Histograma CD138 x CD56

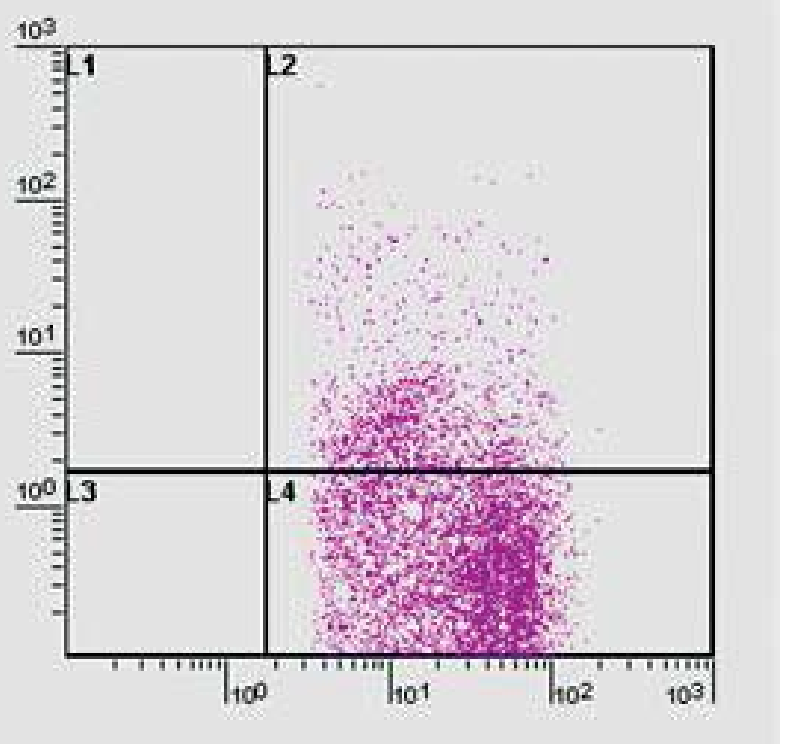

Figura 6. Histograma CD138 x CD45 


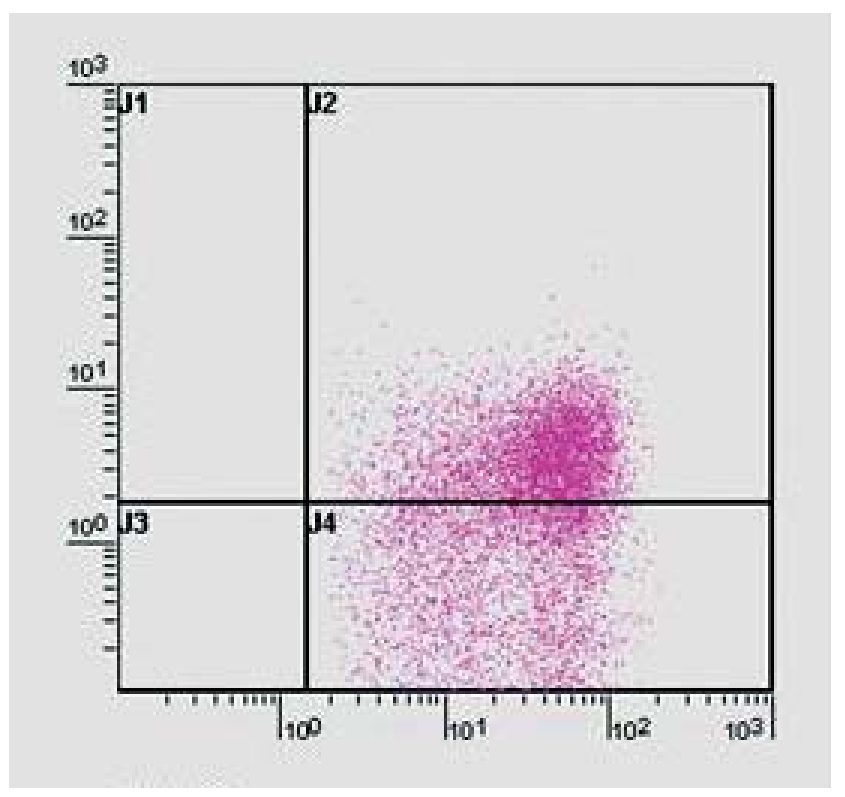

Figura 7. Histograma CD138 x CD33

\section{Resultados}

Neste estudo, o CD38 esteve presente em 95,8\% dos casos com canal médio de expressão de 51,6. O CD56, em $91,3 \%$ dos casos com canal médio de expressão de 22,6. Já o CD19, que normalmente não é expresso nas células do mieloma, foi positivo em apenas $0,4 \%$ dos casos com canal médio de expressão de 6,28. O CD117, que pode ser usado como marcador aberrante, foi encontrado em $25,7 \%$ dos casos com canal médio de 2,83. A cadeia leve da imunoglobulina intracitoplasmática predominante foi do tipo kappa, positiva em 57,5\% dos casos analisados. A expressão de lambda esteve presente em $37,5 \%$ dos casos e em dois (5\%) casos não foi possível realizar a marcação.

$\mathrm{Na}$ análise citogenética tradicional foram detectados quatro (4/25-16\%) casos com alteração cromossômica, sendo uma ausência de Y, um com hiperdiploidia e dois com deleção 13q confirmadas por FISH (Figura 8). Na análise do DNA por citometria de fluxo, sete $(7 / 9-77,8 \%)$ casos apresentaram população aneuplóide e três deles apresentaram uma quantidade elevada de células em fase de síntese (Figura 9).

\section{Discussão}

As células do mieloma, assim como os plasmócitos normais, expressam CD138 e CD38. ${ }^{6}$ Não costumam expressar em sua superfície os antígenos pan-B, como CD19, CD20 e CD22. Nesse aspecto, o MM difere das outras doenças linfoproliferativas de células B que normalmente expressam esses marcadores. ${ }^{7}$

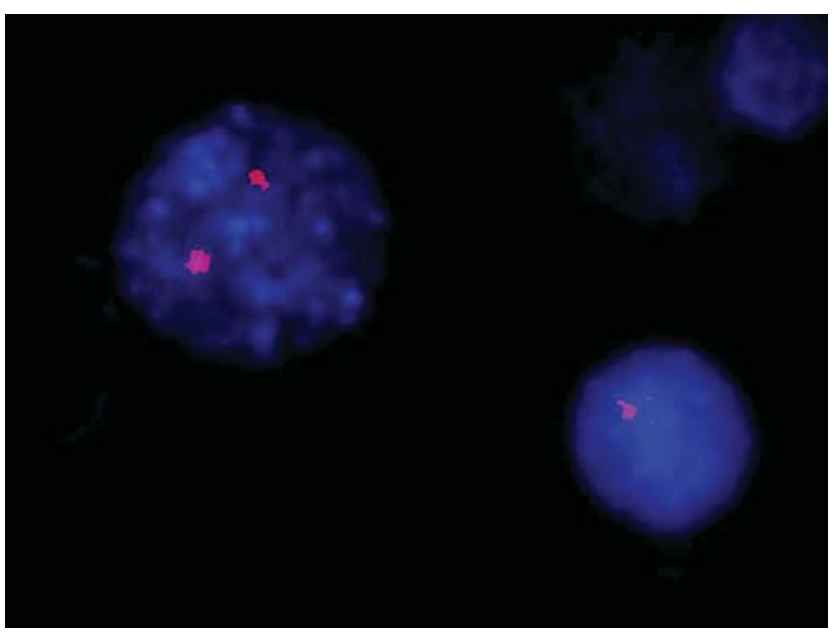

Figura 8. Aplicação da técnica de FISH mostrando uma célula normal (dois sinais) e uma com deleção 13q (um sinal)

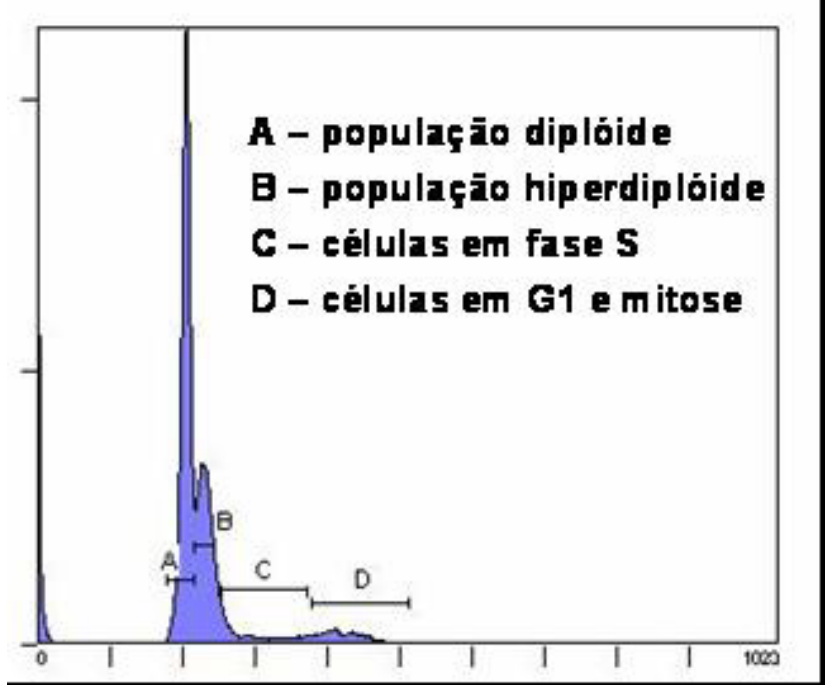

Figura 9. Análise do DNA

A expressão da imunoglobulina é intracitoplasmática e monoclonal. Esse dado é útil no diagnóstico diferencial. Nos casos de linfomas não Hodgkin essa expressão é apenas de superfície e na macroglobulinemia de Waldenström é tanto intracitoplasmática como de superfície. ${ }^{8}$

Uma outra estratégia com CD38(+) e HLA-DR(-) pode ser útil na identificação de plasmócitos anômalos, já que células T ativadas e subgrupos de células B são CD38(+), mas HLA-DR(+). ${ }^{8}$ A forte expressão do CD38, fraca ou ausente expressão de CD45, com a concomitância do CD56 indicam a malignidade. ${ }^{9}$

Nossos dados confirmam que as células mielomatosas apresentam forte expressão de CD38 e CD56, e ausência ou fraca expressão de CD19 e CD117. Houve também um predomínio de cadeia leve do tipo kappa conforme já descrito na literatura. ${ }^{10}$

A identificação de assincronismos maturativos e/ou expressões aberrantes ao diagnóstico é útil na detecção de 
doença residual. A ausência do CD56 e do CD45, ${ }^{11}$ expressão do CD20, CD117 e, mais raramente, do CD33 e marcadores de outras linhagens permitem identificação de uma célula neoplásica em $10^{4}$ a $10^{5}$ células normais. ${ }^{12}$ Essa informação indica a persistência da doença e a necessidade de manutenção da terapia. A Figura 7 mostra um exemplo de histograma com marcação aberrante de CD33.

Foi observado que o percentual de plasmócitos encontrado nos esfregaços de aspirado de medula óssea é freqüentemente superior ao encontrado na análise imunofenotípica por citometria. Isso se deve, em parte, a uma possível diluição na obtenção da amostra e aos prováveis efeitos que o microambiente medular exerce sobre as células do mieloma que acabam dificultando a aspiração.

Deleções ou monossomias envolvendo a região q14 do cromossomo 13 estão diretamente associadas com pior evolução da doença, constituindo fator prognóstico independente. ${ }^{3,13,14}$ A metodologia mais sensível para sua detecção é o FISH, porém, pelo alto custo, muitas vezes, ele não pode ser realizado. Dessa forma, muitos casos com alteração deixam de ser identificados. O estudo do cariótipo por citogenética tradicional também é importante, pois outras anormalidades, além da deleção do cromossomo 13, podem estar presentes apresentando outras implicações no prognóstico.

A maioria dos pacientes que fizeram análise do DNA, por citometria, apresentou aneuploidias. Estudos que também utilizam a citometria de fluxo têm demonstrado que grande parte dos mielomas apresenta esse tipo de alteração cromossômica. ${ }^{15,16,17} \mathrm{O}$ conteúdo de DNA das células neoplásicas, assim como a quantidade de células em proliferação, relacionam-se diretamente com o prognóstico e a evolução da doença. Hiperdiploidias estão associadas com melhor prognóstico, enquanto hipodiploidias indicam pior evolução. ${ }^{3,18}$

Quantidades elevadas de células em fase de síntese também condizem com pior evolução $0^{19,20}$ por traduzirem o índice de proliferação das células neoplásicas. Os valores de referência para esse parâmetro variam de doença para doença de acordo com a capacidade de proliferação da célula envolvida. Os valores significativos para a avaliação do Mieloma Múltiplo ainda não estão bem definidos. Mas, por se tratar de uma doença cujas células apresentam baixa taxa proliferativa, os valores aceitáveis são inferiores aos definidos para outras doenças com altas taxas de proliferação.

Essa quantificação pode ser realizada através de um ensaio imunofluorescente em lâmina que utiliza a bromodeoxiuridina. ${ }^{21}$ Porém, a técnica adaptada à citometria de fluxo com o iodeto de propidium, utilizada nesse estudo, é mais simples e sensível por avaliar uma grande quantidade de células. Alguns estudos importantes utilizaram esta técni$\mathrm{ca}^{19,22,23} \mathrm{e}$ foi constatado que existe grande correlação entre os resultados obtidos através dessas duas metodologias, apesar da maior sensibilidade da técnica que utiliza a citometria.

\section{Conclusões}

A nova estratégia de gates seqüenciais adotada a partir de 2001 possibilitou uma melhor avaliação das células plasmáticas. Comparando-se os histogramas 1 e 2 fica evidente a melhor separação dos plasmócitos quando se utiliza o histograma CD138/Complexidade como referência de análise. A introdução de novos anticorpos que possibilitam a avaliação de marcações aberrantes ao diagnóstico possibilita uma melhor monitorização da remissão fenotípica após o tratamento. Mas, de certa forma, a utilização de um painel mais amplo aumenta o custo do exame.

O estudo cinético do DNA, por citometria, deve ser preconizado para todos os casos diagnosticados, pois tem importância na avaliação prognóstica do MM, por quantificar as células em fase $\mathrm{S}$ e por identificar aneuploidias. Aneuploidias também podem ser identificadas por citogenética tradicional, mas nem sempre são obtidas metáfases para análise. A citometria é uma metodologia mais sensível para essa análise, pois possibilita o estudo de células em intérfase, além de avaliar um número muito maior de células. ${ }^{21}$

As anormalidades cromossômicas influenciam diretamente na evolução do MM e podem auxiliar na escolha da terapia mais adequada. Por esse motivo, o estudo dessas alterações por citogenética tradicional e por FISH, principalmente da deleção 13q, deve ser realizado sempre. O FISH é uma metodologia mais sensível, porém trata-se de um exame caro que depende da utilização de sondas específicas.

Sendo assim, a mudança na estratégia de gates associada a citogenética e ao estudo da cinética do ciclo do DNA permitem melhor identificação de células plasmáticas anômalas, avaliação do prognóstico e detecção de doença residual nos diversos estágios da terapêutica.

\section{Abstract}

Multiple myeloma is a disease with variable natural history, but a clinical fact is that most of the transplanted patients relapse early after transplantation. Minimal residual disease should be one prognostic factor of transplanted patients that could judge if such patients are at risk for early relapse. We diagnosed 50 multiple myeloma cases from 2450 oncohematologic cancer diseases studied between September 1993 and August 2004 (2\% of all cases). Until 2000 these cases were studied using a Coulter Flow Cytometer XLMCL with monoclonal antibodies against CD19, CD38, CD45, CD56, intra-cytoplasmatic and surface kappa and lambda in a Forward Scatter $x$ Side Scatter gate strategy. After 2001 we performed sequential studies using CD138 histogram complexity and monoclonal antibodies anti CD19, CD38, CD56, CD117, intracytoplasmatic kappa and lambda. More recently we included in the antibody pool anti-CD45, anti-HLA-DR and anti-CD33. DNA cytometric studies were performed with the Multicycle software in 9 cases, 7 of those with aneuploidy. G band karyotyping was made in 25 cases and the 13 q deletion was checked in 15 cases. Chromosomal alterations were found in 4 cases including two $13 q$ deletions, confirmed by FISH. Gate choice, cytogenetic studies and cycle 
kinetics of DNA are all data that permit better identification of anomalous plasma cells and therefore detection of minimal residual disease, that probably correlates with relapse prognosis. Rev. bras. hematol. hemoter. 2005;27(1):31-36.

Key words: Multiple myeloma; flow cytometry; cytogenetics; minimal residual disease detection.

\section{Referências Bibliográficas}

1. Bataille R, Harousseau JL. Multiple Myeloma. N Eng J Med 1997; 336:1.657-1.664.

2. Greenlee RT, Hill-Harmon MB, Murray T et al. Cancer Statistics, 2001. Ca Cancer J Clin 2001;51:15-36.

3. Pérez-Simón JA, García-Sanz R, Tabernero MD et al. Prognostic value of numerical chromosome aberrations in multiple myeloma: a FISH analysis of 15 different chromosomes. Blood 1998;91: 3.366-3.371.

4. Durie BGM. Staging and kinetics of multiple myeloma. Semin Oncol 1986;13:300-309.

5. Greer JP, Foerster J, Lukens JN et al. Wintrobe Clinical Hematology. Lippincott Williams and Wilkins: Philadelphia, PA, 2004.

6. Harada H, Kawano MM, Huang $\mathrm{N}$ et al. Phenotypic difference of normal plasma cells from mature myeloma cells. Blood 1993;81: 2.658-2.663.

7. Kyle RA, Robinson RA, Katzman JA. The clinical of biclonal gammopathies. Review of 57 cases. Am J Med 1981;71:999-1.008.

8. Sun T. Flow Cytometric Analaysis of Hematologic Neoplasms. Lippincott Williams and Wilkins: Philadelphia, PA, 2002.

9. Camp BV, Durie BGM, Spier C et al. Plasma cells in multiple myeloma express a natural killer cell-associated antigen: CD56 (NKH-1, Leu10). Blood 1990;76:377-382.

10. Laï J1, Zandecki M, Mary JY et al. Improved cytogenetics in multiple myeloma: a study of 151 patients including 177 patients at diagnosis. Blood 1995;85:2.490-2.497.

11. Moreau P, Robillard N, Avet-Loiseau H et al. Patients with CD45 negative multiple myeloma receiving high-dose therapy have a shorter survival than those with CD45 positive multiple myeloma. Haematologica 2004;89:547-551.

12. Orfão A, San Miguel JF, Almeida J et al. Utilidad del immunofenotipo para la detección de enfermedad mínima residual en pacientes com Mieloma Multiple. VI Congreso de la Sociedad Iberica de Citometria 1999;176.

13. Tricot G, Barlogie B, Jagannath S et al. Poor prognosis in multiple myeloma is associated only with partial or complete deletions of chromosome 13 or abnormalities involving $11 \mathrm{q}$ and not with other karyotype abnormalities. Blood 1995; 86: 4.250.

14. Facon T, Avet-Loiseau H, Guillerm G et al. Chromosome 13 abnormalities identified by FISH analysis and serum 2-microglobulin produce a powerful myeloma staging system for patients receiving high-dose therapy. Blood 2001;97:1.566-1.571.

15. Morgan RJJr, Gonchoroff NJ, Katzmann JA et al. Detection of hypodiploidy using multi-parameter flow cytometric analysis: A prognostic indicator in multiple myeloma. Am J Hematol 1989; 30:195-200.

16. García-Sanz R, Orfão A, González M et al. Prognostic implications of DNA aneuploidy in 156 untreated multiple myeloma patients. Castelano-LeonÃ Cs (Spain) Cooperative Group for the Study of Monoclonal Gammopathies. Br J Haematol 1995;90:106-112.

17. Zandecki M. Multiple Myeloma: Almost all patients are cytogenetically abnormal. Br J Haematol 1996;94:217-227.
18. Smadja NV, Bastard C, Brigaudeau C et al. Hypodiploidy is a major prognostic factor in multiple myeloma. Blood 2001; 98: 2.229-2.238

19. Trendle MC, Leong T, Kyle RA et al. Prognostic significance of Sphase fraction of light-chain-restricted cytoplasmic immunoglobulin (cIg) positive plasma cells in patients with newly diagnosed multiple myeloma enrolled on Eastern Cooperative Oncology Group treatment trial E9486. Am J Hematol 1999;61:232-237.

20. Greipp PR, Lust JA, Katzmann JA et al. The role of beta 2microglobulin, plasma cell labeling index, thymidine kinase and Creactive protein as prognostic factors in 107 cases of multiple myeloma. Blood 1991;78[suppl]: 273a(abst).

21. Greipp PR, Raymond NM, Kyle RA et al. Multiple myeloma: significance of plasmablastic subtype in morphological classification. Blood 1985;65:305-310.

22. San Miguel JF, García-Sanz R, González M et al. A new staging system for multiple myeloma based on the number of S-phase plasma cells. Blood 1995;85:448-4555.

23. Pope B, Brown R, Gibson J et al. The bone marrow plasma cell labeling index by flow cytometry. Cytometry 1999;38:286-292.

Avaliação: Editor e dois revisores externos.

Conflito de interesse: não declarado

Recebido: 25/10/04

Aceito após modificações: 28/03/05 